\title{
Sea Waves Generated by Extratropical Cyclones in the South Atlantic Ocean: Hindcast and Validation against Altimeter Data
}

\author{
ROSMERI PORFÍRIO DA ROCHA \\ Departamento de Ciências Atmosféricas, Universidade de São Paulo, São Paulo, Brazil \\ Shigetoshi Sugahara \\ Instituto de Pesquisas Meteorológicas, and Departamento de Educação, Faculdade de Ciências, Universidade Estadual Paulista, Campus \\ Bauru, São Paulo, Brazil \\ REINALDO BONFIM DA Silveira \\ Instituto Nacional de Meteorologia, Brasilia, Brazil
}

(Manuscript received 20 February 2003, in final form 3 October 2003)

\section{ABSTRACT}

\begin{abstract}
This work presents analyses of the atmospheric conditions and the hindcast of the surface wave field when six extratropical cyclones formed and displaced over the South Atlantic Ocean $\left(10^{\circ} \mathrm{N}, 60^{\circ} \mathrm{S} ; 75^{\circ} \mathrm{W}, 15^{\circ} \mathrm{E}\right)$ between April and September 1999. These events caused high sea waves associated with hazardous conditions along the south and southeast coast of Brazil. The meteorological composite fields for these cyclones show a strong nearsurface wind velocity (up to $14 \mathrm{~m} \mathrm{~s}^{-1}$ ) during its mature phase. The sea-state wave hindcast was obtained using a third-generation wave model forced by the $10-\mathrm{m}$ above ground level wind field from the National Centers for Environmental Prediction-National Center for Atmospheric Research reanalysis dataset. Closer to the south and southeast Brazilian coast, the hindcast results showed significant wave heights of up to $5 \mathrm{~m}$ in some of the events. The wave hindcast results for the significant wave height were compared against satellite altimeter data at $6 \mathrm{~h}$ intervals. The statistical index showed a systematic underestimation of the significant wave height by 0.5 $\mathrm{m}$. The correlation between wave hindcast and altimeter measurements was greater than $90 \%$, showing a good phase reproduction by the wave model.
\end{abstract}

\section{Introduction}

The role of extratropical cyclones in the generation and propagation of the sea waves in the North Atlantic Ocean has been the focus of several investigations (Cardone et al. 1996) and several special observational programs to understand the dynamics of such systems (Hadlock and Kreitzberg 1988). The South Atlantic Ocean also shows extratropical cyclogenesis (Sinclair 1995) in two important regions: one east of Argentina $\left(45^{\circ} \mathrm{S}\right)$ and the other east of Uruguay $\left(30^{\circ} \mathrm{S}\right)$. The South Atlantic cyclones are responsible for the formation of high sea waves over the ocean with economical impacts in the South America region. Cyclones originating in eastern Uruguay are usually associated with an intensification of the near-surface winds from the southeast and create a local phenomenon known as sudestada (Seluchi 1995). The generated sea waves propagate toward the

Corresponding author address: Rosmeri Porfírio da Rocha, Dept. de Ciências Atmosféricas, Universidade de São Paulo, Rua do Matão, 1226, Cid. Universitária, São Paulo 05508-090, Brazil.

E-mail: rosmerir@model.iag.usp.br
Plata River basin and can cause flooding in the city of Buenos Aires, Argentina (Seluchi and Saulo 1998). The cyclones can also cause considerable hardships for the Brazilian population. Brazil has an extensive coastline with a great number of people living and having theirs lives affected by the maritime agitation. For example, Rio de Janeiro, one of the most important cities in Brazil, is frequently affected by high sea waves, causing numerous problems to the population and to the urban infrastructure (Innocentini and Caetano Neto 1996).

An investigation of the sea state during the passage of the intense extratropical cyclone over the South Atlantic was conduced by Innocentini and Caetano Neto (1996) using a second-generation wave model. Their hindcast results showed the generation of high sea waves by the cyclone formed between $30^{\circ}$ and $40^{\circ} \mathrm{S}$, and these waves propagated to the Rio de Janeiro coastal region. However, the lack of significant wave height observations during the period has not allowed the direct verification of the hindcast.

Previous studies regarding the extratropical cyclone sea wave hindcasts and their verification were very lim- 
ited over the South Atlantic Ocean, and dealt mainly with cyclones that propagate high sea waves to the Brazilian shore. Rocha et al. (2000) reported the occurrence of intense sea waves associated with the development of extratropical cyclones in 1999, but they did not present the sea wave hindcast.

An important element in conducting a numerical wave model hindcast is the existence of gridded 10-m above ground level winds with high temporal resolution. The recent reanalysis project of the National Centers for Environmental Prediction-National Center for Atmospheric Research (NCEP-NCAR; Kalnay et al. 1996) allows for a consistent and continuous near-surface wind field for sea state hindcasting (Swail and Cox 2000). Recently, Cox and Swail (2001) performed hindcasts for all oceans of the world using a time scale of $40 \mathrm{yr}$, and they also used some buoys in the North Atlantic and Pacific Oceans for hindcast verification. And for the South Atlantic Ocean, they considered the sea wave comparison for the entire 40-yr period and not individually intense cyclone systems.

One problem for the South Atlantic Ocean hindcast verifications is the limited number of local observational datasets (Innocentini and Caetano Neto 1996). Nevertheless, the recent available altimeter measurements of sea-wave height from the TOPEX/Poseidon (Ocean Topography Experiment; Chelton 1999; hereafter TOPEX) provides an important source of high quality observations (Swail and Cox 2000; Bauer et al. 1992; Young 1999) for the hindcast comparison in the region.

The main goal of this study is to perform the validation of the third-generation wave model WAVEWATCH III (Tolman 1999; Tolman et al. 2002), using reanalysis wind data for intense South Atlantic extratropical cyclones, since very few validations have been performed over this region for such systems. In order to reach this objective, this study performed sea state hindcasts for six extratropical cyclones in the South Atlantic Ocean occurring between April and September 1999. The hindcasts were conducted using the WAVEWATCH III model with surface forcing provided by the $10-\mathrm{m}$ above ground level wind field of the NCEPNCAR reanalysis. The significant wave height hindcasts were evaluated against altimetry observations from TOPEX.

The paper is organized as follows. Section 2 describes the atmospheric and oceanic datasets used in the analysis. A brief meteorological description of the mean atmospheric characteristics during the formation and intensification of the six extratropical cyclones is given in section 3. The third-generation wave model, the hindcast outline, and the verification procedure are presented in section 4. The wave hindcast results along the Brazilian coast and the wave hindcast evaluation are presented in section 5. Finally, section 6 presents the summary and conclusions.

\section{Data sources}

This section describes the atmospheric and significant sea wave height datasets used in this work.

\section{a. Atmospheric data}

The NCEP-NCAR reanalysis dataset (Kalnay et al. 1996) was used to characterize the atmospheric conditions during extratropical cyclone formation and propagation over the South Atlantic Ocean in 1999. This dataset has a horizontal resolution of $2.5^{\circ} \times 2.5^{\circ}$ latitude by longitude, with a temporal resolution of $6 \mathrm{~h}(0000$, 0600, 1200, and 1800 UTC), and 17 pressure levels, from 1000 to $10 \mathrm{hPa}$, as the vertical resolution. The area domain selected to investigate the cyclones was limited between $67.5^{\circ} \mathrm{S}-10^{\circ} \mathrm{N}$ and $72.5^{\circ}-7.5^{\circ} \mathrm{W}$.

The $10-\mathrm{m}$ above ground level winds, also from the NCEP-NCAR reanalysis dataset, were available in a Gaussian grid (horizontal resolution of approximately $1.875^{\circ}$ ). These data were used to identify the cyclone centers and their respective trajectories and to drive the WAVEWATCH III wave model.

\section{b. The sea wave data}

Over the South Atlantic Ocean there is relatively little significant wave height (SWH) data, and in contrast to the North Atlantic and Pacific Oceans there are not longterm daily buoy observations. Only recently (in 2000), through the efforts of the governmental agency the Plano Nacional de Bóias (PNBOIA; information online at www.secirm.mar.mil.br), were some buoys installed along the south coast of Brazil. Another set of SWH observation data at the ocean was gathered from ship records. However, this dataset is not appropriate for verifications for two reasons. First, the SWH observations are visually taken by a human observer and thus they are likely to be imprecise. Second, ships tend to be away from disturbed sea regions for safety reasons and therefore the extreme event observations are very limited and of poor quality.

Thus, the TOPEX altimeter data provide an important source of high quality SWH observations for hindcast verification in the South Atlantic Ocean. Several authors have discussed the high quality of this altimeter dataset (e.g., Swail and Cox 2000; Bauer et al. 1992; Young 1999). The TOPEX altimeter data are also quality controlled, which includes corrections for instrumental errors, environment perturbations (wet and dry tropospheric influences and ionospheric effects), and ocean wave influences (sea state bias). In addition, tide influences (ocean tide and pole tide) and the inverse barometric effect are taken into account (see AVISO/Altimetry 1996 for more details). According to Young (1999) these quality control measures provide an accuracy of $\pm 0.5 \mathrm{~m}$ or $10 \%$, whichever is greater, when compared with the buoy data. 
TABLE 1. Information on the six extratropical cyclones of 1999 examined in the study. The initial and final times, the time of maximum $10-\mathrm{m}$ surface wind, and the total life cycle are presented.

\begin{tabular}{|c|c|c|c|c|}
\hline Cyclone & Initial date & Final date & Time of the $\max 10-\mathrm{m}$ wind & Life cycle $(\mathrm{h})$ \\
\hline $\mathrm{I}$ & 0000 UTC 16 Apr & 0600 UTC 22 Apr & 1800 UTC 17 Apr & 150 \\
\hline II & 0000 UTC 18 May & 0000 UTC 24 May & 0000 UTC 20 May & 144 \\
\hline III & 1800 UTC 28 May & 1200 UTC 02 Jun & 1800 UTC 30 May & 114 \\
\hline IV & 1800 UTC 28 Jun & 0000 UTC 02 Jul & 1200 UTC 30 Jun & 78 \\
\hline $\mathrm{V}$ & 0000 UTC 13 Aug & 0600 UTC 15 Aug & 1200 UTC 14 Aug & 54 \\
\hline VI & 0600 UTC 22 Sep & 1800 UTC 25 Sep & 1800 UTC 23 Sep & 84 \\
\hline
\end{tabular}

The TOPEX dataset is neither simultaneous nor synoptic, so in order to accomplish the hindcast verification, the data points of the TOPEX data (with 6.7-km horizontal resolution along track) were spatially averaged onto a mesh size of $1^{\circ} \times 1^{\circ}$ in latitude and longitude, which corresponds to the resolution of the wave model (section 4). These data were also temporally arranged in 6-h intervals at the synoptic times, using a time window of $\pm 3 \mathrm{~h}$. The TOPEX data were provided by the National Aeronautics and Space Administration's (NASA's) Physical Oceanography Distributed Active Archive Center at the Jet Propulsion Laboratory/California Institute of Technology, via anonymous ftp.

\section{The cyclone identification and mean atmospheric condition}

The criterion for cyclone identification and the mean atmospheric conditions are now described.

\section{a. The cyclone identification}

The trajectory for a two-dimensional field in the $x$ (east-west) and $y$ (north-south) directions can be described by a set of positions, $[x(t), y(t)]$, where $t$ is the time and it is incremented from the first moment when the cyclone is identified until its disappearance. The track of the extratropical cyclones was determined by a procedure similar to that described by Sinclair (1995), which defines the cyclonic track as a sequence of maximum local cyclonic vorticities using the vorticity of the $1000-\mathrm{hPa}$ geostrophic wind, except that this work uses the vorticity of the $10 \mathrm{~m}$ above ground level wind. Applying this procedure, six cyclones associated with strong near-surface winds were then selected for the analyses. These cyclones are hereafter referred to as cyclones I-VI, respectively.

Table 1 presents the initial and final time of each cyclone, their life cycles in hours, and the time when the $10 \mathrm{~m}$ above ground level wind was the most intense over the ocean. The cyclones occurred between April and September 1999 (Table 1), which corresponds with a period of major occurrences of cyclogenesis in the South Atlantic region (Sinclair 1995). The cyclone reported in April (I) was the longest (150 h) and the August $(\mathrm{V})$ cyclone was the shortest $(54 \mathrm{~h})$.

\section{b. The mean atmospheric conditions}

The cyclone trajectories are showed in Fig. 1. Except for event V (Fig. 1f), the cyclones all began their development between $30^{\circ}$ and $35^{\circ} \mathrm{S}$, which is a potential area for cyclogenesis. During the first 4 days, cyclone I was quasi stationary, staying near the south Brazilian coastline. Only in the last $24 \mathrm{~h}$ of its life cycle did cyclone I move to the northeast (Fig. 1a). Cyclones II (Fig. 1b), III (Fig. 1c), and IV (Fig. 1d) present a typical trajectory for the South Atlantic region, that is, eastward or southeastward displacement moving farther away from their original position. On the other hand, cyclones V (Fig. 1e) and VI (Fig. 1f) describe a different trajectory, moving northward.

Figure 2 displays the time series of the cyclonic relative vorticity of the $10-\mathrm{m}$ wind at the center of the cyclones during their life cycles. Cyclones I and III were the most intense, and showed minimum relative vorticity below $-7 \times 10^{-5} \mathrm{~s}^{-1}$.

At least two observed conditions influenced the formation of such cyclones: first a high-level jet stream and second an area of mass divergence associated with a high-level trough at $200 \mathrm{hPa}$. This pattern was obtained by making a composite average of the six events, using the cyclone centers as a reference. This composite used 21 grid points in the meridional and zonal directions and was performed at the initial time and at the time when the 10-m surface wind reached its maximum (sees Table 1). For each of the six cyclones the composite position is indicated in Fig. 1.

Although the averaging process smoothed the meteorological field, the composite is very useful for analyzing the synoptic conditions at different stages of development. At $200 \mathrm{hPa}$ the streamlines show a trough associated with a cyclone at the surface (to the east of the trough), between two anticyclones (Fig. 3a). The two anticyclones include the subtropical anticyclone to the northeast of the cyclone center and a polar anticyclone to the southwest. At this initial time the sea level pressure shows a cyclone composite with two minimum centers with pressures of $1011 \mathrm{hPa}$ (Fig. 3a). The vertical inclination (west) of the upper-level trough to the surface cyclone would favor the intensification of the cyclone at the surface. In the initial phase of the cyclone the 10-m surface wind was not intense with a speed of 

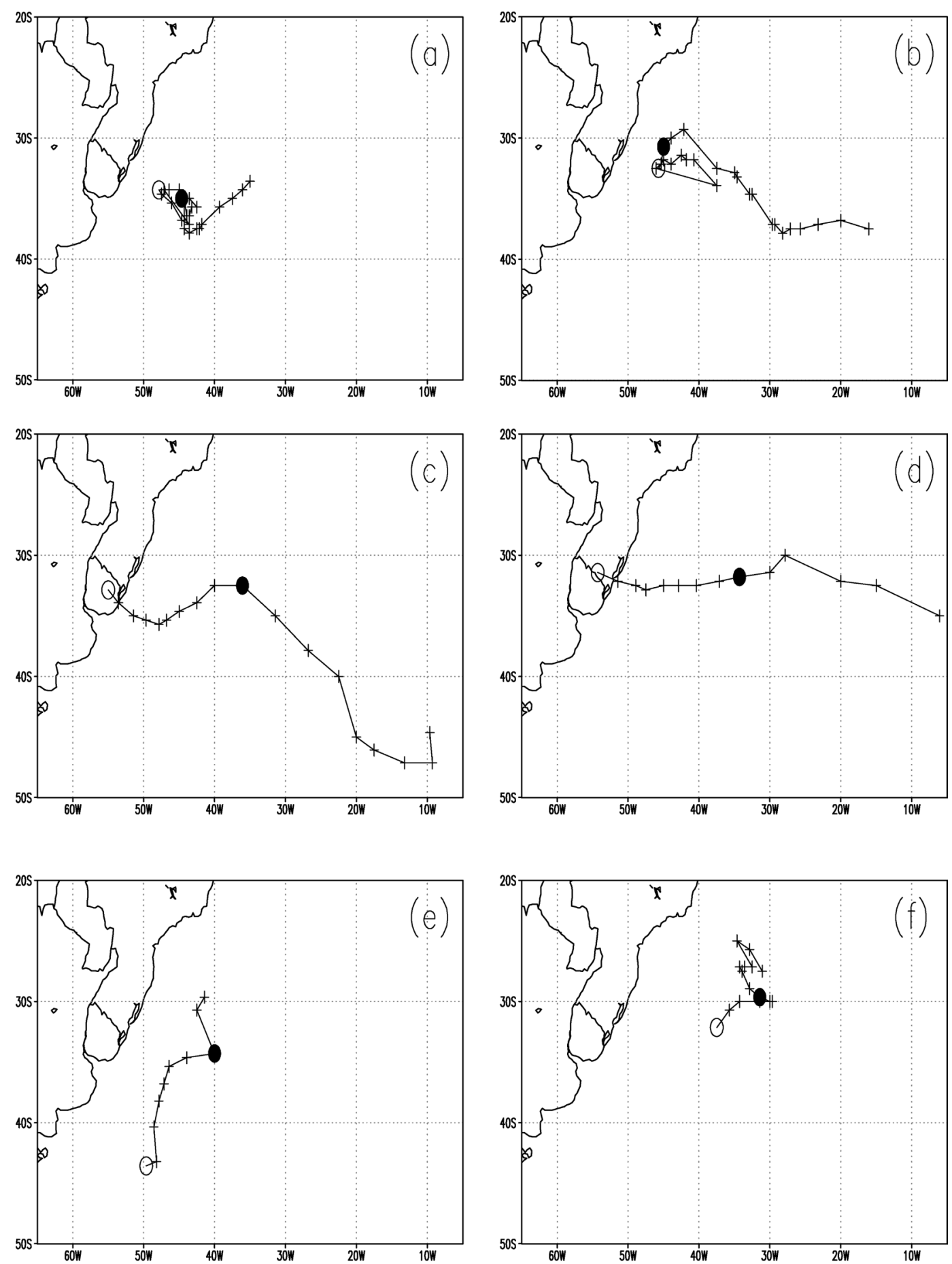

FIG. 1. The cyclones trajectories are indicated by crosses (+) every $6 \mathrm{~h}$ for cyclones (a) I, (b) II, (c) III, (d) IV, (e) V, and (f) VI. The open and closed circles represent the positions of the cyclones at initial and mature phases, respectively.

$\sim 4 \mathrm{~m} \mathrm{~s}^{-1}$ around a large area surrounding the cyclone (Fig. 3b).

Figures $4 \mathrm{a}$ and $4 \mathrm{~b}$ show the composite fields for the time when the $10-\mathrm{m}$ winds reached their highest speeds in the vicinity of the cyclones. The times and positions for the composites are indicated in Table 1 and Fig. 1a, respectively. The 200-hPa streamlines continue to show a trough (Fig. 4a), and at this time depict a larger amplitude than in the initial field (Fig. 3a). The surface cyclone is now represented by only one center with a 


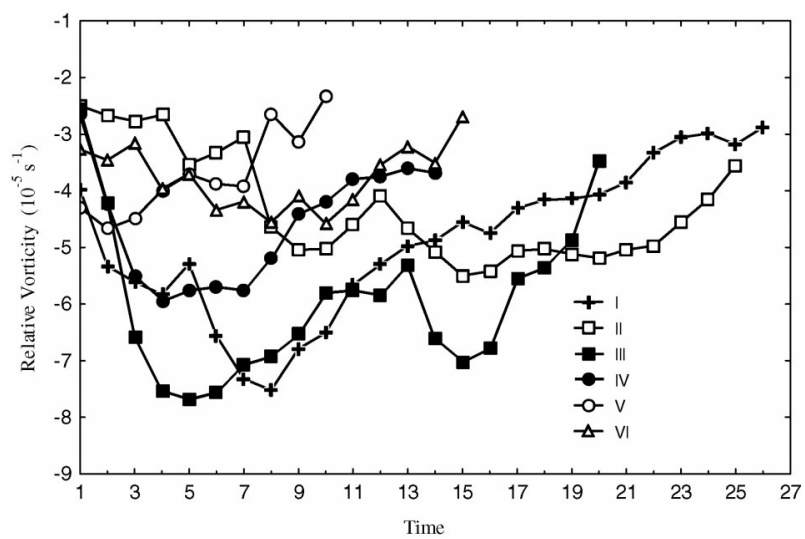

FIG. 2. Time series of the $10-\mathrm{m}$ wind cyclonic vorticity $\left(10^{-5} \mathrm{~s}^{-1}\right)$ for cyclones I-VI: The time interval at each point is $6 \mathrm{~h}$ after the initial time for each cyclone.
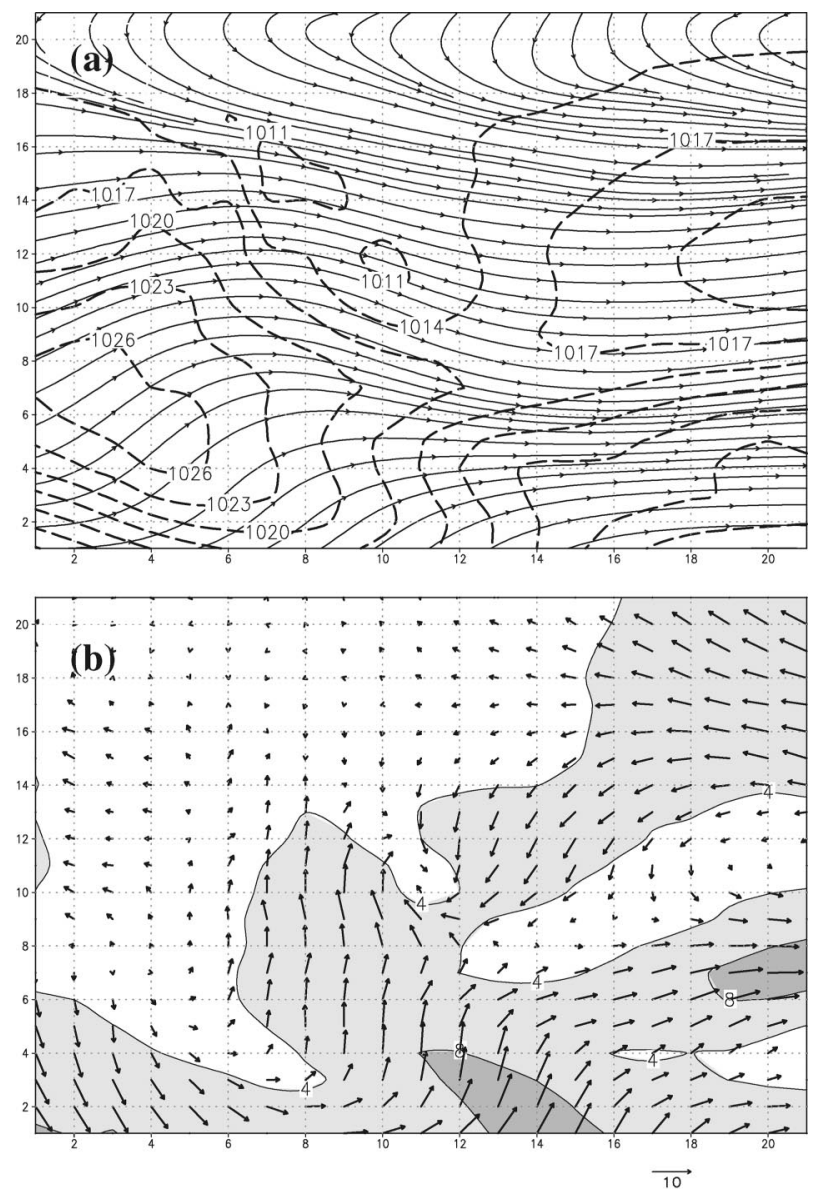

FIG. 3. Composite average of the six cyclones at the initial stage: (a) $200-\mathrm{hPa}$ streamlines (continuous line) and the mean sea level pressure (dashed line at each $3 \mathrm{hPa}$ ) and (b) 10-m surface wind field (arrows) and intensity (continuous lines at each $4 \mathrm{~m} \mathrm{~s}^{-1}$ ). Dark shaded areas represent winds above $8 \mathrm{~m} \mathrm{~s}^{-1}$.
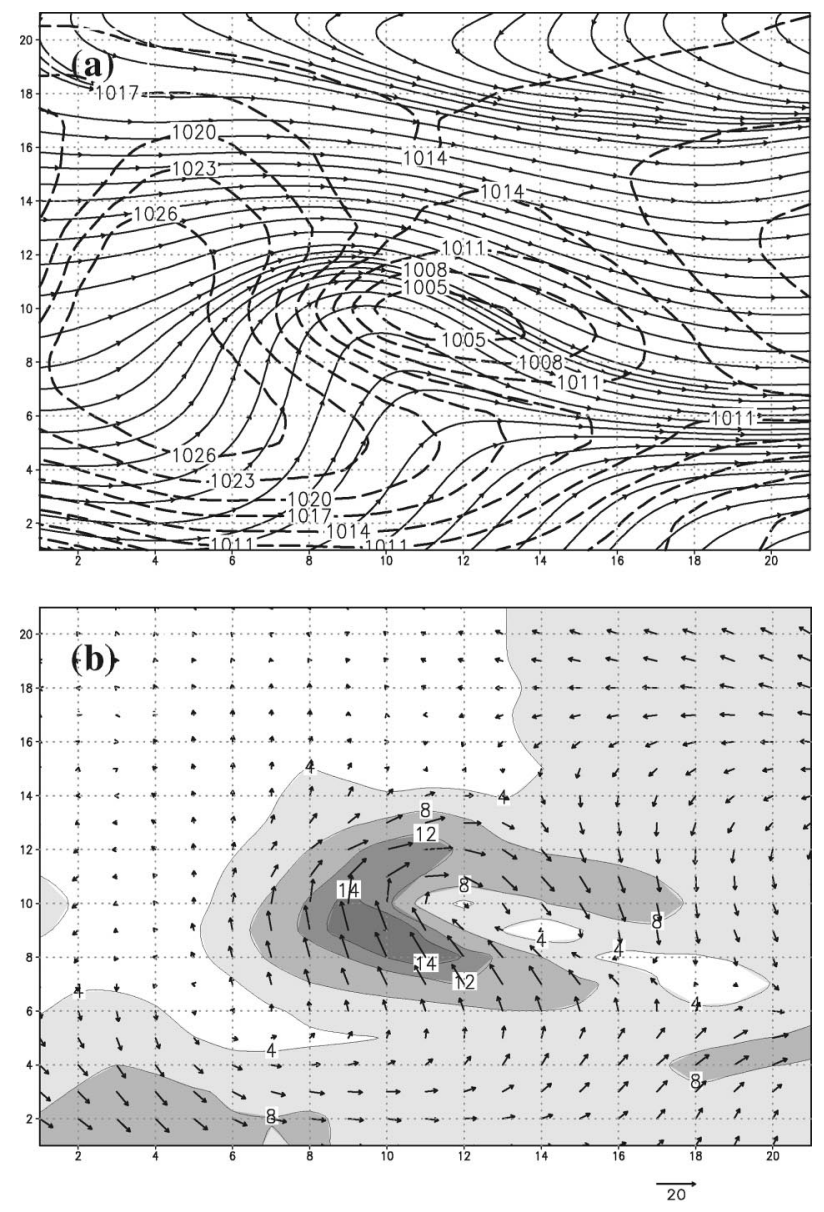

FIG. 4. As in Fig. 3 but for the time of the most intense 10-m surface wind.

pressure of $1005 \mathrm{hPa}$, but the center still remains on the east side of the 200-hPa trough. The anticyclone to the west of the cyclone sustains the same intensity as in the initial stage, that is, $1026 \mathrm{hPa}$ (Fig. 4a). The anticyclone did propagate northward and contributed to the intensification of the pressure gradient in the southern and western sectors of the cyclone.

The composite $10-\mathrm{m}$ surface wind velocities exceeded $14 \mathrm{~m} \mathrm{~s}^{-1}$ in the southwest sector of the surface cyclone (Fig. 4b), where the wind is intense over a long horizontal fetch. Only southeast sector wind velocities were less than $8 \mathrm{~m} \mathrm{~s}^{-1}$.

\section{Wave model hindcasts}

\section{a. Wave model description}

This study used the third-generation wave model WAVEWATCH III (Tolman 1999; Tolman et al. 2001) from NCEP to hindcast the sea wave state for the six cyclones described in the section 3. In the WAVEWATCH III model, the evolution of the directional wave spectrum is a function wavenumber $(k)$ and direction 


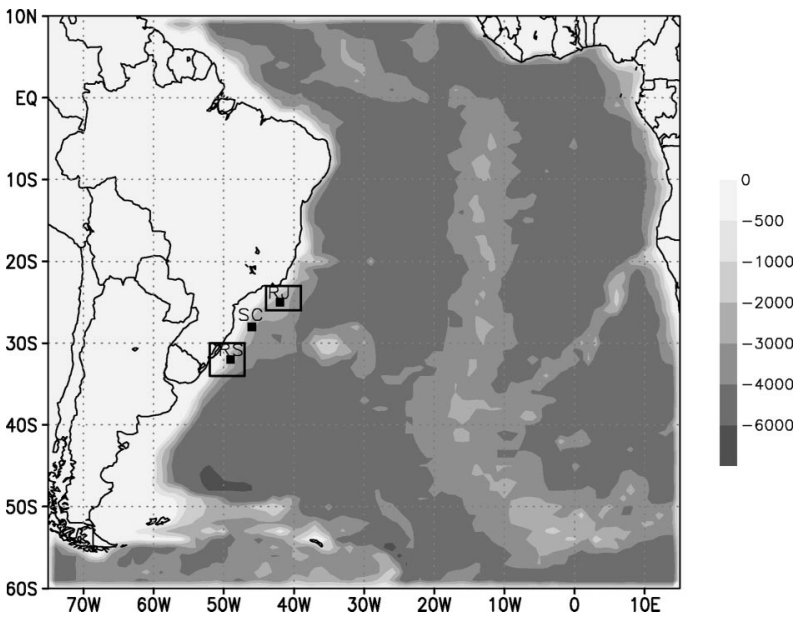

FIG. 5. WAVEWATCH III hindcast domain and bathymetry (m, shaded). The figure also displays the points Rio Grande do Sul (RS), Santa Catarina (SC), and Rio de Janeiro (RJ), in addition to the two defined areas for the hindcast comparison.

$(\theta)$ in spherical coordinates defined by the latitude and longitude. The propagation due to the group velocity and the action of the source terms determines the evolution of the wave spectrum. The following source terms are considered in the model: wind-wave interaction, nonlinear wave-wave interaction, dissipation (whitecapping), and bottom friction. This last term is represented by the linear Joint North Sea Wave Project (JONSWAP) parameterization (Hasselmann et al. 1973). The formulation proposed by Tolman and Chalikov (1996) is used to represent the input and dissipation terms, while the nonlinear wave-wave interactions are resolved according to Hasselmann et al. (1985).

To solve the physical processes and to save computational time, WAVEWATCH III uses a time-splitting scheme (Tolman 1999) with four different time steps. The global time step is used for the input winds and to propagate the entire solution in time. The spatial propagation equation is solved using a third-order-accurate scheme and the time step can be smaller or equal to the global time step. The third-order-accurate scheme is also used in the integration of the intraspectral propagation. In this case, the time step also can be smaller (shallowwater grid) or equal (deep-water grid) than the global time step. For numerical integration of the source terms a modified version of the semi-implicit scheme is used.

The WAVEWATCH III model was implemented on a regular grid of $1^{\circ} \times 1^{\circ}$ in latitude and longitude. The model domain extends over the South Atlantic Ocean, from $60^{\circ} \mathrm{S}$ to $10^{\circ} \mathrm{N}$, and from $75^{\circ} \mathrm{W}$ to $15^{\circ} \mathrm{E}$ as shown in Fig. 5. Figure 5 also shows the bathymetry and the locations of some areas referred to in the text. Finally, the WAVEWATCH III model ran with a directional resolution of $30^{\circ}$ and 25 frequencies [through the geometric progression $f(n+1)=1.1 f(n)$, where $f(1)=0.04$ $\left.\mathrm{s}^{-1}\right]$.
TABLE 2. The start and end times, and total duration of the hindcasts for cyclones I-VI. The time of the maximum SWH in the hindcast results is also presented.

\begin{tabular}{cllcc}
\hline \hline Cyclone & Start date & End date & $\begin{array}{c}\text { Total } \\
\text { duration (h) }\end{array}$ & $\begin{array}{c}\text { Time and date of } \\
\text { max SWH }\end{array}$ \\
\hline I & 14 Apr & 23 Apr & 216 & 0600 UTC 18 Apr \\
II & 16 May & 25 May & 216 & 1200 UTC 21 May \\
III & 26 May & 02 Jun & 168 & 0000 UTC 31 May \\
IV & 26 Jun & 02 Jul & 144 & 1200 UTC 30 Jun \\
V & 11 Aug & 17 Aug & 144 & 1200 UTC 14 Aug \\
VI & 19 Sep & 27 Sep & 192 & 0600 UTC 24 Sep \\
\hline
\end{tabular}

\section{b. Hindcasts}

The SWH and the wave direction were output every $6 \mathrm{~h}$. The 10-m surface wind fields of the NCEP-NCAR reanalysis dataset at 6-h intervals were used to force the WAVEWATCH III model. Recently, Swail and Cox (2000) pointed out that this dataset provides better results for the North Atlantic Ocean wave hindcasting than the $1000-\mathrm{hPa}$ and lowest sigma level (0.995) wind fields.

The start and end times for each hindcast are presented in Table 2. One can observe that the total duration of each hindcast is event dependent: it was longer for events I and II (216 h) than events IV and V (144 h). The start time of each experiment was set to 0000 UTC for the days presented in Table 2, which corresponds to about $48 \mathrm{~h}$ before the cyclone's initial time. This allowed the wave model to spin up the sea waves.

Table 2 also provides the date of the hindcast's maximum SWH near the southern and southeastern coasts of Brazil. These dates were determined through a visual inspection of the SWH at each 6-h interval.

Statistical indexes were calculated to compare the hindcast results with the TOPEX measurements (section $5 b)$. Consider a variable $X$, where the subindexes $M$ and $O$ indicate the model value and observation, respectively. The bias $b$ is computed by

$$
b=\frac{1}{N} \sum_{i=1}^{N}\left(X_{M i}-X_{O i}\right),
$$

and the correlation coefficient, $r$, is given by

$$
r=\frac{\sum_{i=1}^{N}\left(X_{M i}-\overline{X_{M}}\right)\left(X_{O i}-\overline{X_{O}}\right)}{\sqrt{\sum_{i=1}^{N}\left(X_{M i}-\overline{X_{M}}\right)^{2} \sum_{i=1}^{N}\left(X_{O i}-\overline{X_{O}}\right)^{2}}},
$$

where the overbar is used to indicate the average and $N$ is the amount of data. The root-mean-square error is

$$
\mathrm{rms}=\left[\frac{1}{N} \sum_{i=1}^{N}\left(X_{M i}-X_{O i}\right)^{2}\right]^{1 / 2} .
$$

\section{The hindcast results}

This section presents the hindcast results of the surface wave field for the south and southeast Brazilian 
coastal area and the comparison with altimetry data from TOPEX.

\section{a. The near Brazilian shore sea waves}

Figures $6 \mathrm{a}-\mathrm{f}$ present the hindcast results of the SWH and the direction of propagation of the sea waves at the time of maximum marine agitation for each of the six cyclones (see Table 2). These figures show a large area, close to the Brazilian coast, where the SWH is higher than $4 \mathrm{~m}$. The sea waves propagated toward the Brazilian shore from south (Figs. 6a-c and 6e), southeast (Figs. 6b, 6d, and 6f), and southwest (Figs. 6c-e). Near the coast, the highest sea wave was hindcast at event number III (Fig. 6c), where the SWH was greater than $7 \mathrm{~m}$. For event II, there is a coincidence between the time of maximum marine agitation (as defined in section 4b) and the TOPEX overpass as shown in Fig. 6b. The high sea waves obtained with WAVEWATCH III are in phase with those observed by TOPEX. However, near the area of maximum SWHs the hindcast presents a lower SWHs than does the TOPEX data. For other cyclones there are TOPEX overpasses near the time and area of the intense sea waves (see section $5 b$ ).

A cyclonic circulation (clockwise) can be noted in the wave field (Figs. 6a-f), which is in agreement with the composite 10-m surface wind field (Fig. 4b). This kind of pattern is less pronounced for events V (Fig. 6e) and VI (Fig. 6f).

The time evolution of the sea state near the Brazilian shore was investigated by using time series of SWHs, at three selected points located at the Rio Grande do Sul (RS, at $32^{\circ} \mathrm{S}, 49^{\circ} \mathrm{W}$ ), Santa Catarina (SC, at $28^{\circ} \mathrm{S}$, $46^{\circ} \mathrm{W}$ ), and Rio de Janeiro (RJ, at $25^{\circ} \mathrm{S}, 42^{\circ} \mathrm{W}$ ) (see locations in Fig. 5). These locations represent important coastal regions that are impacted economically and that were most affected by the presence of the extratropical cyclones.

Figures $7 \mathrm{a}-\mathrm{f}$ present the hindcast time series of the SWHs for cyclones I-VI, respectively, in the three points along the Brazilian shore. Cyclones I-V showed that the SWH increased first at RS, the southernmost point, and then at SC and RJ, respectively. They also show that there is a time lag between the maximum at $\mathrm{RS}$ and at SC, which varies from 6 (cyclone $\mathrm{V}$ ) to 18 $\mathrm{h}$ (cyclones II and IV). A time lag was also noted between RS and RJ. For event II and IV the time lag was the same as that for RS and SC, and for events III and $\mathrm{V}$ it was $6 \mathrm{~h}$ larger.

Cyclone VI formed far from the coast and to the north (see Fig. 1) in comparison to the other five cyclones and the SWH temporal evolution (Fig. 7f) showed some differences. The maximum SWH reached 3.9, 3.1, and $2.5 \mathrm{~m}$ at RJ, SC, and RS (Fig. 7f), respectively. The results showed that the higher sea waves affected RJ more than the other points, which is different from the other five cyclones.

Table 3 summarizes the maximum SWHs as well as the duration time that the SWHs exceeded $3.0 \mathrm{~m}$, for the six cyclones and at the three reference points. The results in this table show that cyclone III produced the highest values of SWH at all three points. However, individually, the maximum SWH hindcast was $6.5 \mathrm{~m}$ at RS for cyclone I. On the other hand, cyclone II was the one that had SWHs higher than $3.0 \mathrm{~m}$ during a long period (up to $48 \mathrm{~h}$ at all points).

Two areas within the model domain, close to the Brazilian shore, are used to perform the comparison between hindcast results and TOPEX observations. The first area is near RS (between $30^{\circ}-34^{\circ} \mathrm{S}$ and $47^{\circ}-52^{\circ} \mathrm{W}$ ), corresponding to the south coast (see Fig. 5). The second is near RJ and represents the conditions at the southeast coast of Brazil (between $23^{\circ}-26^{\circ} \mathrm{S}$ and $39^{\circ}-44^{\circ} \mathrm{W}$; see Fig. 5). Figures $8 \mathrm{a}$ and $8 \mathrm{~b}$ show the SWHs for the south and southeast coasts, at the model grid point, and the maximum SWH around the point in the $\pm 1^{\circ}$ of the latitude by longitude grid.

For the six cyclones at the south coast, there is a good relation between the SWH hindcast and the TOPEX dataset (Fig. 8a), mainly for the periods where the sea waves are high. In addition, in periods of low SWHs the hindcast results tend to be lower than those from the TOPEX data. The bias between the time series dataset is lower when the TOPEX data are compared to the maximum SWH hindcast in the area surrounding the grid points (Fig. 8a).

The time series for the southeast coast (Fig. 8b) also shows good agreement between TOPEX observations and hindcast results. There is only one TOPEX data point in the area for event IV. Also along the southeast coast, the SWH bias is smaller when TOPEX data are compared to the WAVEWATCH III maximum near to the grid point. It is important to note that the phase of the time evolution is roughly the same between the hindcast results (maximum or grid point value) and the TOPEX observations. Thus, the comparison to the maximum affects only the bias rather than the correlation between time series.

\section{b. The hindcast verification}

WAVEWATCH III hindcast results showed that the cyclones were associated with high sea waves at the south and southeast Brazilian shores (section 5a). The SWH hindcast is now objectively compared to the TOPEX data. In order to avoid swell propagation problems near the boundaries, the comparison was performed excluding $10^{\circ}$ around the boundaries in the WAVEWATCH III domain. It was also important to note that the regional model application without the boundary data has a systematic lack of background swells that systematically contributes to a negative bias. The inclusion of near-boundary points in the verification tends to reduce the correlation coefficient and increase the root-mean-square error between the hindcast and the TOPEX data. Thus for this verification, the domain was 

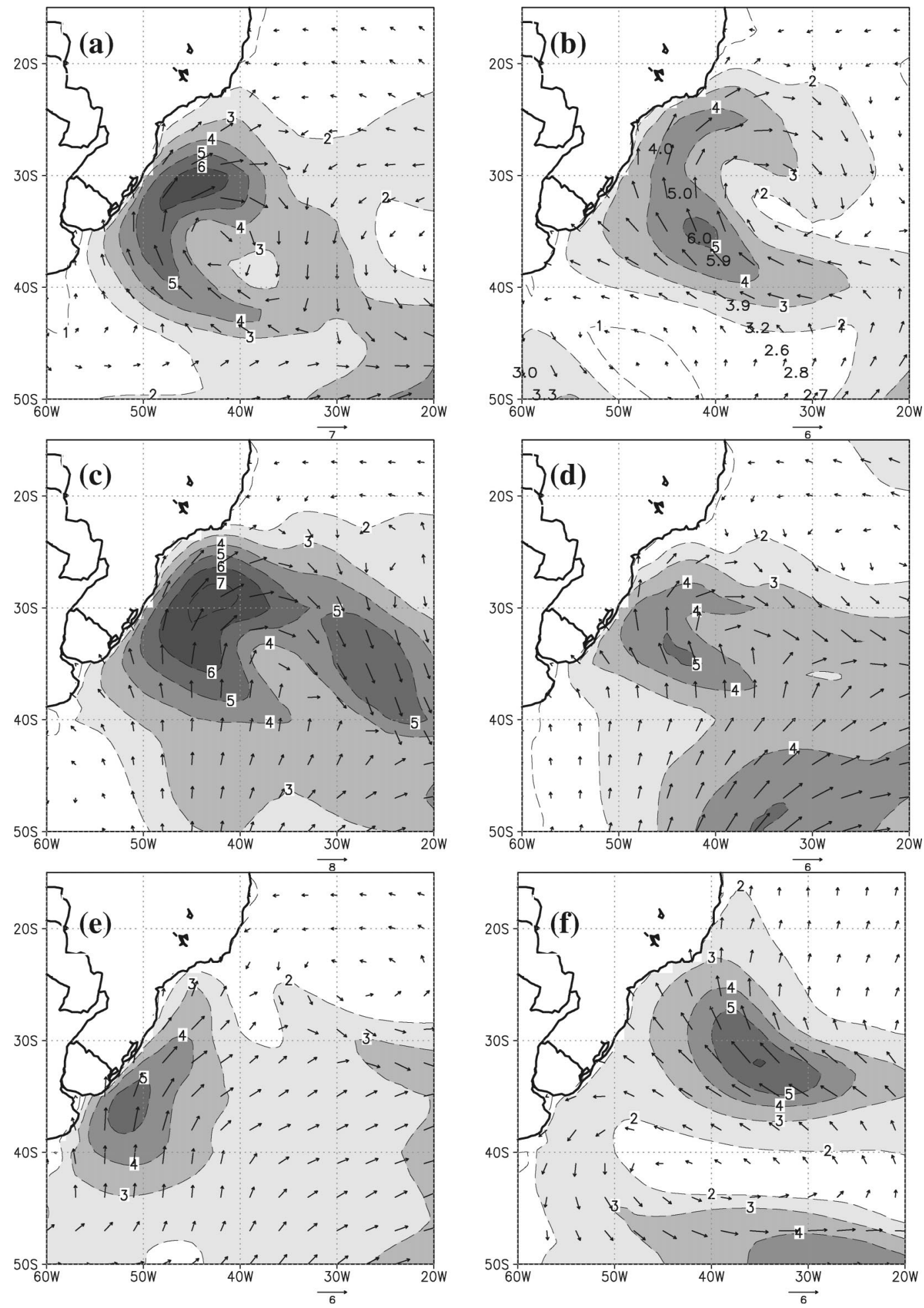

FIG. 6. Hindcast of the SWH (shaded areas) and wave direction (arrows) for cyclones (a) I at 0600 UTC 18 Apr, (b) II at 1200 UTC 21 May, (c) III at 0000 UTC 31 May, (d) IV at 1200 UTC 30 Jun, (e) V 1200 UTC 14 Aug, and (f) VI at 0600 UTC 24 Sep. The numbers plotted in the northwest-southeast orientation in (b) represent the SWHs for the TOPEX overpass. The shaded areas are in $1-\mathrm{m}$ increments. 

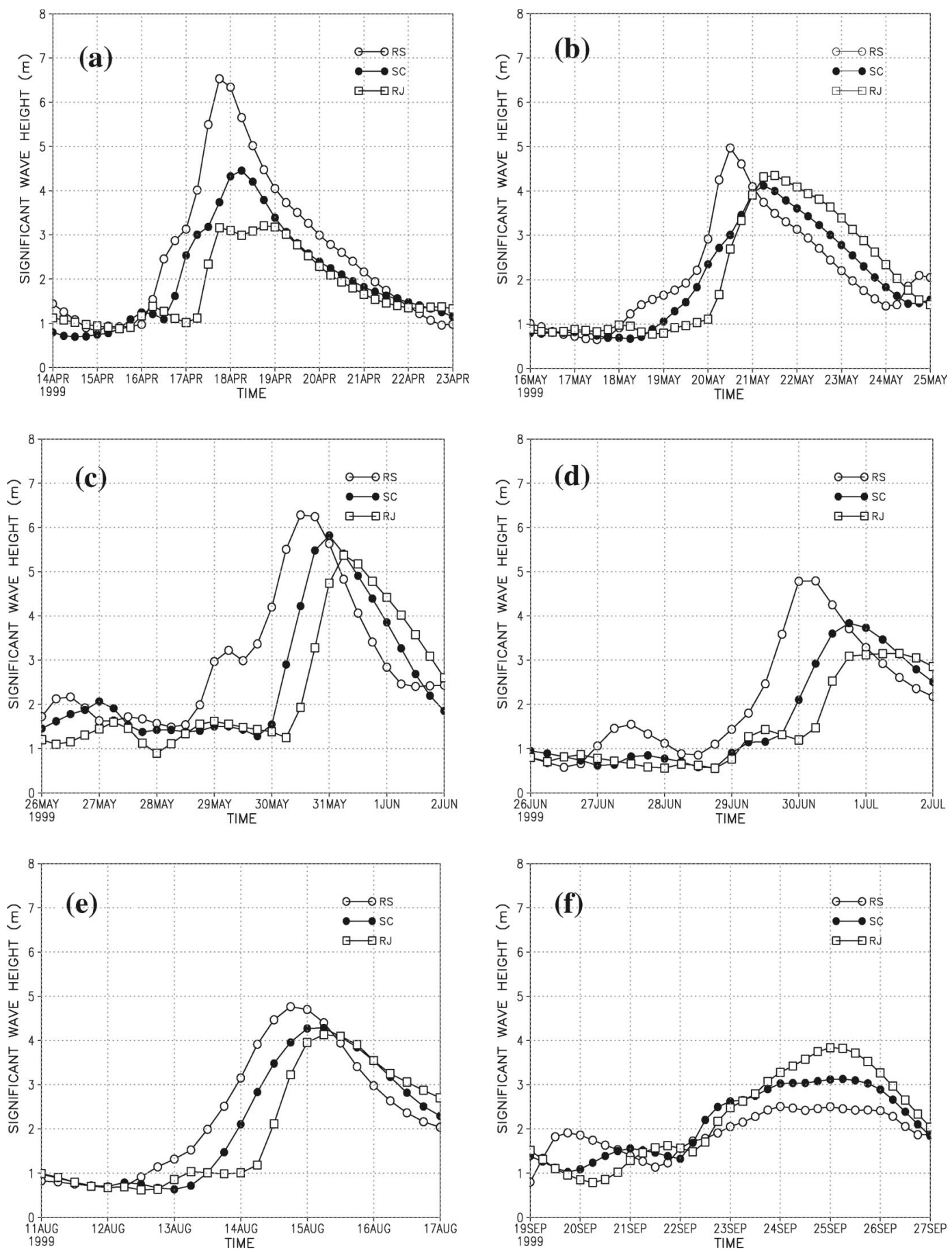

FIG. 7. Hindcast time series of SWHs for the RS, SC, and RJ points near the Brazilian shore for cyclones (a) I, (b) II, (c) III, (d) IV, (e) V, and (f) VI.

considered to be between $50^{\circ} \mathrm{S}-0^{\circ}$ and $65^{\circ} \mathrm{W}-5^{\circ} \mathrm{E}$ for all of the data available $48 \mathrm{~h}$ after the hindcast initial time. The reader should note that the number of verification points depends on the event; that is, it is larger than 1800 for cyclone II and only 128 for cyclone VI. The total number of points for comparison is 6557 for all six cyclones.
Figure 9 shows the error distribution (WAVEWATCH III - TOPEX) of the SWHs considering all points. It is possible to note that the hindcast performed well $80 \%$ of the time, when the error was between -1.0 and +0.5 $\mathrm{m}$. The overall performance shows that less than $5 \%$ of the absolute values of the errors are greater than $2.0 \mathrm{~m}$. On the other hand, the negative errors happen more 
TABLE 3. Summary of the SWH hindcast results at points RS, SC, and RJ for cyclones I-VI. The point locations are given in Fig. 5.

\begin{tabular}{ccccccccc}
\hline \hline & \multicolumn{3}{c}{$\begin{array}{c}\text { No. of h with SWH } \\
\text { higher than } 3 \mathrm{~m}\end{array}$} & & \multicolumn{3}{c}{ Max SWH (m) } \\
\cline { 2 - 4 } \cline { 7 - 8 } Cyclone & RS & SC & RJ & & RS & SC & RJ \\
\hline I & 72 & 48 & 36 & & 6.5 & 4.5 & 3.2 \\
II & 54 & 54 & 72 & & 5.0 & 4.2 & 4.5 \\
III & 72 & 48 & 48 & & 6.2 & 5.8 & 5.5 \\
IV & 42 & 30 & 30 & & 4.8 & 4.0 & 3.2 \\
V & 48 & 48 & 48 & & 4.8 & 4.3 & 4.2 \\
VI & 0 & 18 & 48 & & 2.5 & 3.1 & 3.9 \\
\hline
\end{tabular}

often than the positive ones. This shows a systematic underestimation of the WAVEWATCH III hindcast of $\mathrm{SWH}$, at on average $0.47 \mathrm{~m}$. The high correlation coefficient (0.9) obtained for all compared data is also indicative of the good performance of WAVEWATCH III for the intense extratropical cyclones. Despite the fact that the bias is apparently high, two important points should be considered. First, the bias is of the same order of magnitude as the TOPEX SWH accuracy (Young $1999, \pm 0.5 \mathrm{~m})$. Second, the selected cases are intense events and this tends to increase the differences between the observations and the hindcast results. The obtained bias is near the one found by Swail and Cox (2000) for the hindcast over the North Atlantic Ocean. In that study, they used the NCEP-NCAR reanalyses 10-m surface wind field data and verified four hindcast months against altimeter observations. In addition, Tolman et al. (2002), in a verification of a 24-h forecast, using the global WAVEWATCH III model compared to the $E u$ ropean Remote Sensing Satellite-2 (ERS-2), also showed a negative bias (smaller than -0.15) in a large extension of the Atlantic, north of $30^{\circ} \mathrm{S}$ (see Fig. 7a of Tolman et al. 2002). And for point comparison, they found a negative bias $(-0.01 \mathrm{~m})$ between $30^{\circ} \mathrm{N}$ and $30^{\circ} \mathrm{S}$ and a positive bias $(0.10 \mathrm{~m})$ to the south of $30^{\circ} \mathrm{S}$, but they used more than 195000 points, while in this work we used only 6557 points.

The good quality of the hindcast was also verified by examining individually each cyclone. Figures 10a-f show the hindcast and the TOPEX SWHs for cyclones I-VI, respectively, organized as separated tracks indicated by vertical arrows. The hindcasts realistically capture rapid changes in the $\mathrm{SWH}$, which are shown to be in phase with the observational data. This is reflected in the overall correlation coefficient of about 0.9 and it indicates the close proximity between the two series of data. Only cyclone VI shows a correlation of less than 0.8 , and this lower value is probably the result of the smaller sample size (Fig. 10f).

Although the WAVEWATCH III model performed well, errors were high in some cases. Event III (near count 9; Fig. 10c) showed an underestimation of more than $100 \%$. These higher SWH values, which were not captured by the hindcast, had important implications in the bias, which for cyclone III is $-0.65 \mathrm{~m}$. However,
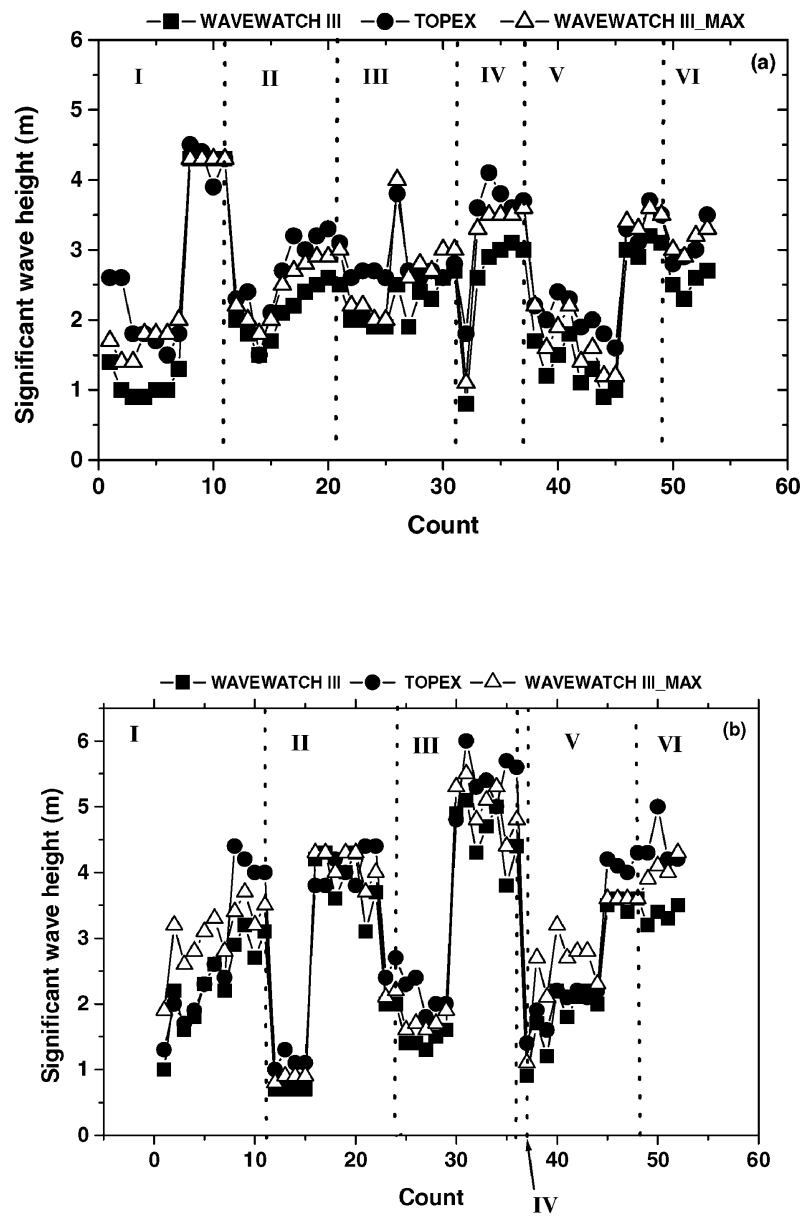

FIG. 8. Hindcast of the SWHs and TOPEX data near the (a) south and (b) southeast coast of Brazil.

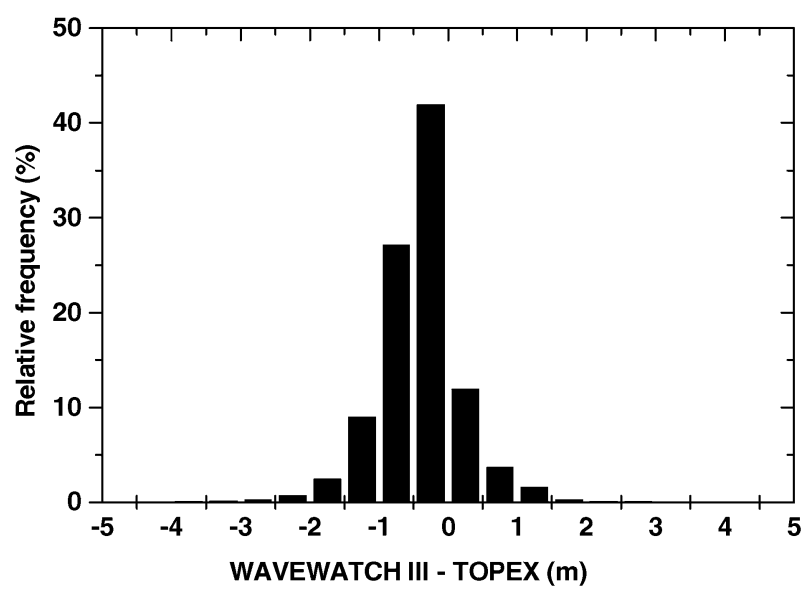

FIG. 9. SWH error distribution frequency. The error is defined as the difference between WAVEWATCH III and TOPEX. 

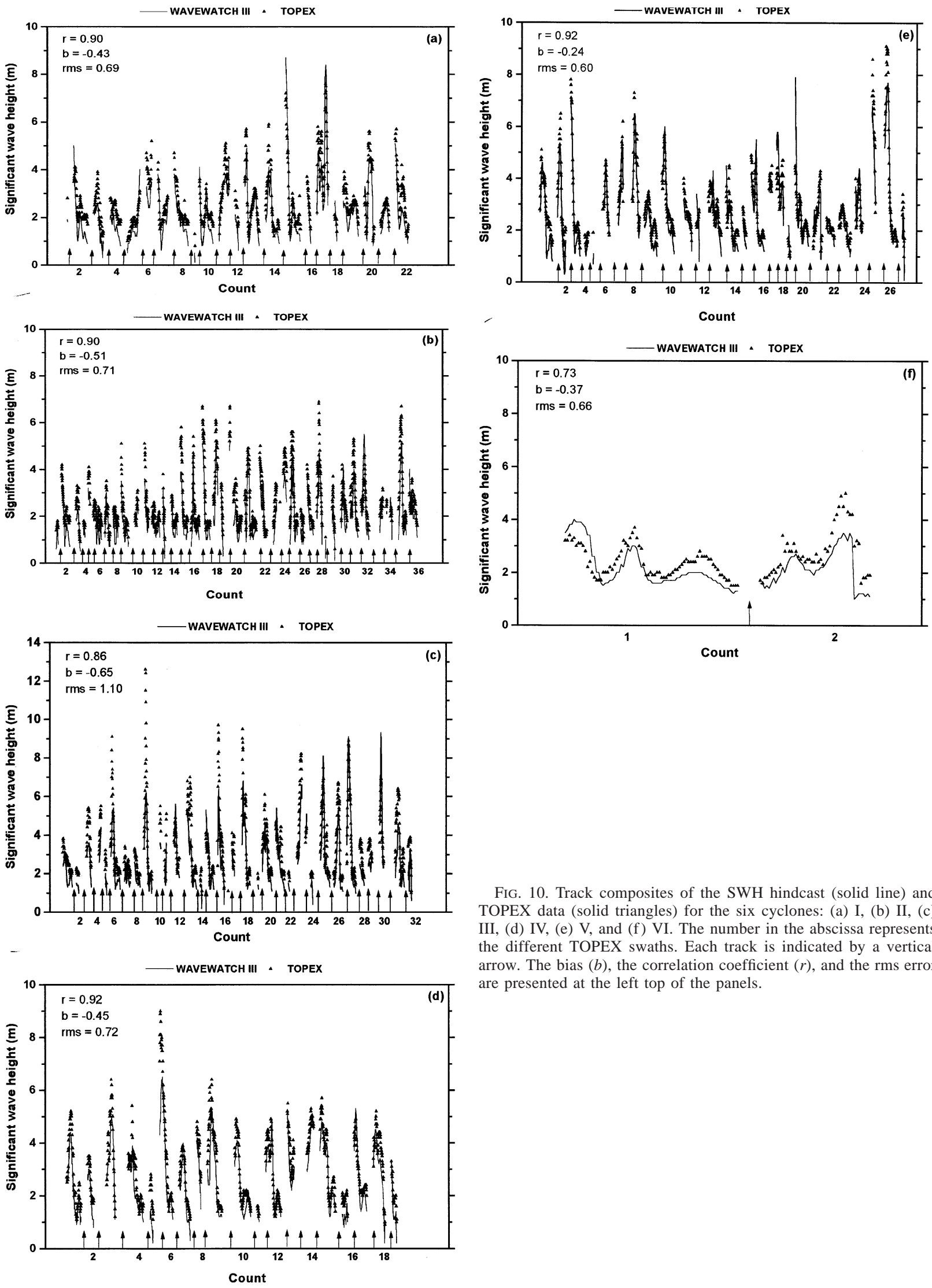

FIG. 10. Track composites of the SWH hindcast (solid line) and TOPEX data (solid triangles) for the six cyclones: (a) I, (b) II, (c) III, (d) IV, (e) V, and (f) VI. The number in the abscissa represents the different TOPEX swaths. Each track is indicated by a vertical arrow. The bias $(b)$, the correlation coefficient $(r)$, and the rms error are presented at the left top of the panels. 
TABLE 4 . The bias $(b)$, rms error, and correlation coefficient $(r)$ for SWHs and near-surface wind speed from WAVEWATCH III hindcasts and TOPEX data. The statistical indices were calculated for SWH $<$ $5 \mathrm{~m}$ and $\mathrm{SWH} \geq 5 \mathrm{~m}$

\begin{tabular}{cccccccc}
\hline \hline & \multicolumn{3}{c}{ SWH } & & \multicolumn{3}{c}{ Wind } \\
\cline { 2 - 4 } \cline { 6 - 8 } \cline { 6 - 8 } & $b$ & Rms & $r$ & & $b$ & Rms & $r$ \\
\hline$<5 \mathrm{~m}$ & -0.41 & 0.66 & 0.86 & & -0.66 & 2.56 & 0.71 \\
$\geq 5 \mathrm{~m}$ & -1.05 & 1.59 & 0.70 & & -3.41 & 4.51 & 0.69 \\
\hline
\end{tabular}

other extreme values of SWH, as for instance counts 3 and 26 in cyclone $\mathrm{V}$ (Fig. 10c), were better hindcast and the overall bias was consequently smaller, that is, $-0.24 \mathrm{~m}$.

Figures $10 \mathrm{a}-\mathrm{f}$ also illustrate that the SWH for a calm sea state is always smaller in WAVEWATCH III hindcasts than in the TOPEX data, and this factor also contributed to the negative bias.

One reason for the SWH hindcast underestimation is the intensity of the $10-\mathrm{m}$ surface wind data from the NCEP-NCAR reanalysis, which is used to drive the WAVEWATCH III model. The bias and the rms for the SWH values below and above $5 \mathrm{~m}$ was computed separately (Table 4). For SWHs below $5 \mathrm{~m}$ these statistics are -0.41 and 0.66 , respectively. For SWHs above 5 $\mathrm{m}$, they are -1.05 and 1.59 , respectively. On the other hand, the same indices were computed for the 10-m wind from the NCEP-NCAR reanalysis data and for the 19.5-m wind from the TOPEX data. Both the bias and the rms for the wind are considerably greater when the $\mathrm{SWH}$ is higher than or equal to $5 \mathrm{~m}$. Thus, it is likely that the underestimated SWH values found in the hindcast are associated with the underestimated 10-m wind intensity from the NCEP-NCAR reanalysis data. The sea wave hindcast is very dependent on the $10-\mathrm{m}$ wind quality used to drive the wave model (Swail and Cox 2000; Cardone et al. 1996; Cavaleri and Bertotti 1997). The hindcasting of extreme events is even more difficult, and in some cases the utilization of the wind buoy observations to analyze the $10-\mathrm{m}$ wind helps in improving the wave hindcasts (Swail and Cox 2000; Cardone et al. 1996). For example, Swail and Cox (2000) found a reduction of $50 \%$ in the bias with the utilization of this procedure. However, this approach was not possible in the South Atlantic Ocean due to the lack of regular buoy observations.

Table 5 presents a contingency table that brings the results of a cross comparison between WAVEWATCH III hindcasts and TOPEX data, using an SWH of $3 \mathrm{~m}$ as threshold. The hit rate scored $86.5 \%$, the false alarm rate scored $1.3 \%$, and the error rate was $12.2 \%$. The error happened when WAVEWATCH III did not hindcast SWHs higher than $3 \mathrm{~m}$. This simple test indicates that the model can be well applied to an alert system, considering the hit rate as performance of the model.
TABLE 5. Contingency table between hindcasts and TOPEX data using $\mathrm{SWH}$ of $3.0 \mathrm{~m}$ as the threshold value.

\begin{tabular}{lcc}
\hline \hline \multirow{2}{*}{$\begin{array}{c}\text { WAVEWATCH III } \\
\text { hindcast }\end{array}$} & \multicolumn{2}{c}{ TOPEX data } \\
\cline { 2 - 3 } & $\mathrm{SWH} \geq 3 \mathrm{~m}$ & $\mathrm{SWH}<3 \mathrm{~m}$ \\
\hline $\mathrm{SWH} \geq 3 \mathrm{~m}$ & $1651(25.2 \%)$ & $83(1.3 \%)$ \\
$\mathrm{SWH}<3 \mathrm{~m}$ & $803(12.2 \%)$ & $4020(61.3 \%)$ \\
\hline
\end{tabular}

\section{Summary and conclusions}

During the year 1999 strong surface winds were produced near the Brazilian coast in the South Atlantic Ocean, as a consequence of extratropical cyclone activity. The six events responsible for the high sea waves were identified for atmospheric analyses and surface wave field hindcasts.

The three-dimensional characteristics of the atmosphere during the development of the six extratropical cyclones over the South Atlantic Ocean, between April and September 1999, were examined through the use of NCEP-NCAR reanalysis data. The composite atmospheric fields showed weak cyclonic circulation at low levels in the initial phase of the cyclone. In this initial phase, the 10-m surface wind field was weak, about 4 $\mathrm{m} \mathrm{s}^{-1}$. At high levels, however, a trough and a jet stream, on the western side of the surface cyclone, helped in the intensification and maintenance of these cyclones. In the mature phase, the vertical inclination of the highlevel trough with respect to the surface cyclones decreased. However, the composite surface cyclone at this time is more intense than at initial stage. The presence of a strong polar anticyclone, southwest of the surface cyclone, increases the intensity of the near-surface wind on the west side of the cyclone. The intensity of the 10$\mathrm{m}$ surface wind is up $14 \mathrm{~m} \mathrm{~s}^{-1}$ on the south and west sides of surface cyclone.

The hindcast of the sea state was performed using the third-generation wave model driven by the $10-\mathrm{m}$ wind field from the NCEP-NCAR reanalysis data. The results showed high sea waves when the six cyclonic events moved over the South Atlantic Ocean. These waves propagated toward the south and southeast Brazilian coast where SWH hindcasts were above $5 \mathrm{~m}$.

The hindcast verification was performed using the TOPEX SWH observations. Considering all six of the cyclones the verification showed a bias of less than -0.5 $\mathrm{m}$ and a correlation coefficient of 0.9. This high correlation shows that WAVEWATCH III forced by $10 \mathrm{~m}$ above ground level NCEP-NCAR reanalysis winds can very well simulate the phase of the SWH when compared to TOPEX data.

We speculate that these bias values are due to low spatial resolution and the intensity of the near-surface wind. Unfortunately, for past cases, the use of a more appropriate wind field for wave hindcasts, as proposed by Cardone et al. (1996) and Swail and Cox (2000), is very difficult to apply in the South Atlantic Ocean, due to the low density of near-surface observations. Nev- 
ertheless, the recent installation of a buoy network, through PNBOIAS, will make possible the reanalysis of the wind field for current and future events on wave hindcasting procedures.

In this work the statistical results were conjectured to be associated with the coarse spatial and temporal near-surface wind field resolution. However, what was not discussed was the sensitivity of these statistics to the variation of the WAVEWATCH III resolution. To address this issue, we plan to perform a sensitivity analysis of the WAVEWATCH III model in both frequency and direction, as well as horizontal resolution, using the same extratropical systems in a future work.

Acknowledgments. We thank Dr. Valdir Innocentini of INPE for the installation and operation of the wave model and for the computational support. The NWS/ NCEP Marine Modeling and Analysis Branch provided access to the WAVEWATCH III model. We also thank Jacyra Soares, Adalgiza Fornaro, and Carlos Morales for important comments. Many thanks are given to NASA and NCEP-NCAR for the TOPEX/Poseidon altimeter dataset and the reanalysis data, respectively, which are available in the public domain. This research was partially supported by FAPESP grants, under Contract 95/04573-5R. One of the authors, RPR, wishes to thank the CNPq for the partial fellowship under Contract $380515 / 00-8$.

\section{REFERENCES}

AVISO/Altimetry, cited 1996: AVISO user handbook for merged TOPEX/POSEIDON products. 3d. ed. AVI-NT-02-101. [Available online at http://www.jason.oceanobs.com/html/donnees/ produits/handbooks_uk.html.]

Bauer, E., S. Hasselmann, K. Hasselmann, and H. Graber, 1992: Validation and assimilation of Seasat altimeter wave heights using the WAM wave model. J. Geophys. Res., 97, 12 671-12 682.

Cardone, V. J., R. E. Jensen, D. T. Resio, V. R. Swail, and A. T. Cox, 1996: Evaluation of contemporary ocean wave models in rare extreme events: The "Halloween storm" of October 1991 and the "storm of the century" of March 1993. J. Atmos. Oceanic Technol., 13, 198-230.
Cavaleri, L., and L. Bertotti, 1997: In search of the correct wind and wave fields in a minor basin. Mon. Wea. Rev., 125, 1964-1975.

Chelton, D. B., 1999: Report of the high-resolution ocean topography science working group meeting. College of Oceanic and Atmospheric Sciences, Oregon State University, Corvallis, OR, 220 pp.

Cox, A. T., and V. R. Swail, 2001: A global wave hindcast over the period 1958-1977: Validation and climate assessment. J. Geophys. Res., 106, 2313-2329.

Hadlock, R., and C. W. Kreitzberg, 1988: The Experiment on Rapidly Intensifying Cyclones over the Atlantic (ERICA) field study: Objectives and plans. Bull. Amer. Meteor. Soc., 69, 1309-1320.

Hasselmann, K., and Coauthors, 1973: Measurements of wind-wave growth and swell decay during the Joint North Sea Wave Project (JONSWAP). Dtsch. Hydrogr. Z., 8A (12), 1-95.

Hasselmann, S., K. Hasselmann, J. H. Allender, and T. P. Barnett, 1985: Computations and parameterizations of the nonlinear energy transfer in a gravity-wave spectrum. Part II: Parameterizations of the nonlinear energy transfer for applications in wave models. J. Phys. Oceanogr., 15, 1378-1391.

Innocentini, V., and E. S. Caetano Neto, 1996: A case study of the 9 August 1998 South Atlantic storm: Numerical simulations of the wave activity. Wea. Forecasting, 11, 78-88.

Kalnay, E., and Coauthors, 1996: NCEP/NCAR 40-Year Reanalysis Project. Bull. Amer. Meteor. Soc., 77, 437-471.

Rocha, R. P., S. Sugahara, and V. Innocentini, 2000: Marine cyclones over South Atlantic Ocean during 1999 winter. Part I: Their structure, intensity and evolution. Preprints, Sixth Int. Conf. on Southern Hemisphere Meteorology and Oceanography, Santiago, Chile, Amer. Meteor. Soc., 200-201.

Seluchi, M. E., 1995: Diagnóstico y pronóstico de situaciones sinópticas conducentes a ciclogénesis sobre el este de Sudamérica. Geofis. Int., 34, 171-186.

_ plosive coastal cyclogenesis over South America: Experiments using a limited area model. Aust. Meteor. Mag., 47, 309-320.

Sinclair, M. R., 1995: A climatology of cyclogenesis for the Southern Hemisphere. Mon. Wea. Rev., 123, 1601-1619.

Swail, V. R., and A. T. Cox, 2000: On the use of NCEP-NCAR reanalysis surface marine wind fields for a long-term North Atlantic wave hindcast. J. Atmos. Oceanic Technol., 17, 532-545.

Tolman, H. L., 1999: User manual and system documentation of WAVEWATCH-III version 1.18. NOAA/NWS/NCEP-NCAR/ OMB Tech. Note 166, 110 pp. [Available online at http:// polar.ncep.noaa.gov/waves/wavewatch.]

— wind wave model. J. Phys. Oceanogr., 26, 2497-2518.

— , B. Balasubramaniyan, L. D. Burroughs, D. Chalikov, Y. Y. Chao, H. S. Chen, and V. M. Gerald, 2002: Development and implementation of wind-generated ocean surface wave models at NCEP. Wea. Forecasting, 17, 311-333.

Young, I. R., 1999: Wind Generated Ocean Waves. Oxford University Press, 288 pp. 